\title{
The neurotoxicity of toluene: EEG changes in rats exposed to various concentrations
}

\author{
Y. TAKEUCHI AND N. HISANAGA \\ From the Department of Hygiene, Nagoya University School of Medicine, 65 Tsurumai-cho, Showa-ku, \\ Nagoya, Japan
}

ABSTRACT Workers exposed to toluene develop many central and autonomic nervous symptoms. It has been suggested that the effects of toluene on the central nervous system may be detectable by EEG. In the present experiments, changes in EEG and behaviour of rats exposed to toluene were monitored in an attempt to clarify the relationship between exposure to toluene and central nervous system reaction. Chronically implanted electrodes were used in Wistar albino male rats to record EEG in cortex and hippocampus, cervical EMG and pulse rate. The rats were exposed to $4000 \mathrm{ppm}$, $2000 \mathrm{ppm}$ and $1000 \mathrm{ppm}$ toluene vapour for four hours. The sleep cycle was divided into five phases (wakeful, spindle, slow-wave, preparadoxical and paradoxical) judged by the cortical and hippocampal EEGs, the cervical EMG, and behaviour. This classification should be useful in assessment of the effects of toluene on the central nervous system. In our experiments, the changes in the sleep cycle suggest that $4000 \mathrm{ppm}$ and $2000 \mathrm{ppm}$ of toluene vapour disturb the sleep, and $1000 \mathrm{ppm}$ of toluene vapour prevents sleep entering the slow-wave phase but facilitates its entry into the paradoxical phase. The changes of EEG components were peculiar to each concentration. The results suggest, in effect, that analysis of the changes in the EEG components would be helpful as an index to the reaction of the central nervous system to toluene vapour.

Many workers who have been exposed to organic solvents, especially toluene, develop non-specific symptoms of the central and autonomic nervous systems, such as headache, heaviness of the head, giddiness, forgetfulness, insomnia, fatigue, lassitude, loss of appetite, nausea, palpitation and impotence. However, the usual clinical examination seldom brings to light specific and objective signs. Nevertheless, abnormal EEGs in workers with toluene exposure have been reported by some authors (Andersen and Kaada, 1953; Hirano, 1972a, b, c; Mabuchi et al., 1972, 1974; Giuliano et al., 1974). Abnormal EEGs, together with decreased convulsion thresholds, and dysfunction of the diencephalonhypophysis-adrenal cortex system have also been observed in workers who had been exposed to toluene (Takeuchi et al., 1972a). These reports suggest that the central nervous system may be affected by organic solvents, particularly toluene, and that the effects may be detectable in the EEG. Nevertheless, only a few of the studies reported have been de-

Received for publication 24 November 1976 Accepted for publication 16 June 1977 signed to clarify experimentally the relation between cause and effect (Takeuchi et al., 1972b; Fordor et al., 1973; Suzuki, 1973; Takeuchi and Suzuki, 1975).

The experiments reported in this paper were designed to study changes in EEG and behaviour of rats exposed to various concentrations of toluene vapour.

\section{Methods}

The EEG, EMG and pulse rate were recorded in Wistar albino male rats with chronically implanted electrodes. The animals were housed individually in $22 \times 22 \times 22 \mathrm{~cm}$ stainless steel cages, and were freely provided with the standard food 'oriental MF' and water. The 19 rats were divided into four groups; the control group, and those groups which were to be exposed to 1000 or $2000 \mathrm{ppm}$ toluene each comprised five rats, whereas the $\mathbf{4 0 0 0}$ ppm group comprised four rats. All rats were prepared for the experiments under nembutal anaesthesia; their initial average body weight was $343 \pm 35 \mathrm{~g}$.

Silver balls of about $1 \mathrm{~mm}$ in diameter were used as 

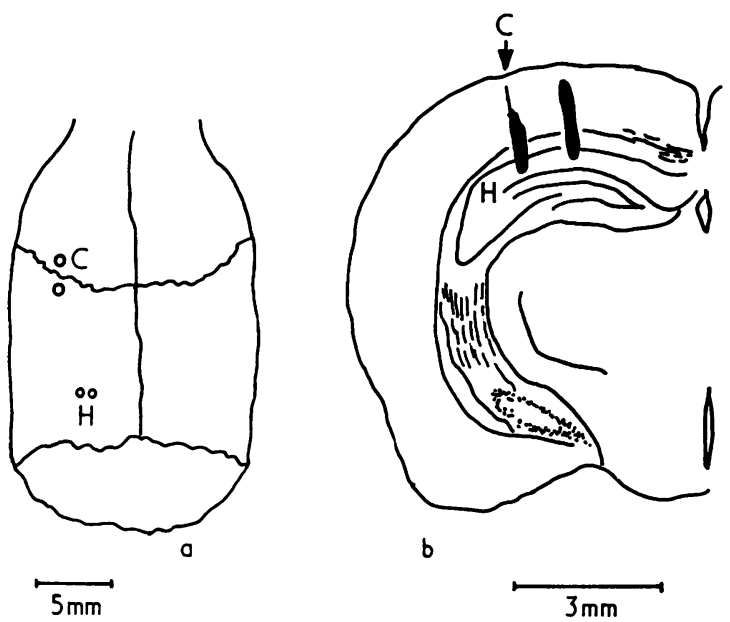

Fig. 1 Location of recording electrodes in the rat skull (a) and hippocampus (b). $C=$ cortex; $H=$ hippocampus.

electrodes for cortical EEGs. These balls were placed on the dura mater through two burr holes on either side of the coronal suture about $2 \mathrm{~mm}$ apart and about $5 \mathrm{~mm}$ to the left of the sagittal suture. The burr holes for the hippocampal electrodes were drilled $3 \mathrm{~mm}$ to the left of the sagittal suture and $3 \mathrm{~mm}$ in front of the lambdoid suture. Acupuncture needles of about $0.2 \mathrm{~mm}$ diameter were used as hippocampal electrodes. All but the tips of the needles were insulated with Japanese lacquer and inserted through holes in the skull at $1 \mathrm{~mm}$ intervals to a depth of 3.5 $\mathrm{mm}$, following the anatomical guide of König and Klippel (1963). The locations of recording electrodes in the rat skull and hippocampus are shown in Fig. 1. Silver balls of about $1 \mathrm{~mm}$ in diam-ter were placed on both sides of the cervical muscles to record the EMG and pulse rate by subcutaneous wires leading to the skull. All electrodes were ultimately connected to the pins of a miniature socket, which was fixed to the skull with dental carboxylate cement (Durelon). Biopotentials were recorded by a 9-channel EEG apparatus (ME-5; Nihon-Koden).

The wired-up rats were placed in a $22 \times 22 \times 44$ cm stainless steel cage in the $50 \times 50 \times 145 \mathrm{~cm}$ exposure chamber (Maeda, 1968). The EEG chart speed was usually $1.5 \mathrm{~cm} / \mathrm{sec}$, occasionally $3 \mathrm{~cm} / \mathrm{sec}$. Cortical and hippocampal EEGs were continuously monitored by an EEG frequency analyser (MF-4 and MF-5; Nihon-Koden). The behaviour of the rats during the experiments was transmitted by television to the observation room.

The rats were exposed to $4000 \mathrm{ppm}, 2000 \mathrm{ppm}$ and $1000 \mathrm{ppm}$ toluene vapour respectively and the concentrations in the chambers were monitored by gas-liquid chromatography, which showed that the actual concentrations by analysis were $4160 \pm 130$ ppm, $2240 \pm 170 \mathrm{ppm}$ and $1030 \pm 120 \mathrm{ppm}$ respectively. Exposure was for four hours, from 1100 am to $300 \mathrm{pm}$, and the biopotentials and behaviour of the rats were recorded from 1000 am to $500 \mathrm{pm}$ during both the day of exposure and the preceding day. Rats in the control group, although confined to the same type of chamber as the toluene-exposed rats, breathed fresh air only.

\section{Results}

The experiments were carried out during daylight hours, because the rat, being a nocturnal animal, shows an increasing tendency to spontaneous sleep at this time. The sleep cycles were divided into five phases with regard to the EEG, EMG of cervical muscles and behaviour of the rats (Fig. 2) according to the criteria of Roldán et al. (1963), Jouvet (1967), and Timo-Iaria et al. (1970).

During the wakeful phase, cortical and hippocampal EEGs showed a fast and low voltage. The EMG was of high amplitude and the pulse was rapid. The rat walked, scratched himself, ate, drank and kept his eyes open even while he lay quiet.

During the spindle phase, the cortical EEG showed spindles mixed in fast and low voltage, and the hippocampal EEG showed an irregular, slow and high voltage. The EMG was of medium amplitude and the pulse was slightly accelerated. The rat lay quietly with the eyes half-open or closed, but with the neck raised.

During the slow-wave phase, both EEGs showed an irregular, slow and high voltage. The EMG was small in amplitude and the pulse was slow. The rat lay quietly with eyes closed.

During the preparadoxical phase, the cortical EEG showed high spindles mixed in a slow and high voltage, and that of the hippocampus showed synchronized $\theta$ waves of $7-8 \mathrm{~Hz}$. The amplitude of the EMG was small and the pulse was slightly faster than in the slow-wave phase. The rat lay quietly with eyes closed.

During the paradoxical phase, the cortical EEG showed a fast and low voltage, and that of the hippocampus showed regular $\theta$ waves of 7-8 Hz. EMG amplitude was reduced almost to the isoelectric line, indicating a total loss of muscular tone, and the pulse was slower than in any other phase. The rat lay with eyes closed and with head and trunk on the floor.

Changes in the sleep cycle were observed continuously from 1100 am to $500 \mathrm{pm}$, during the four hours' exposure and the first two hours subsequently. The results are shown in Fig. 3. The percentage of 

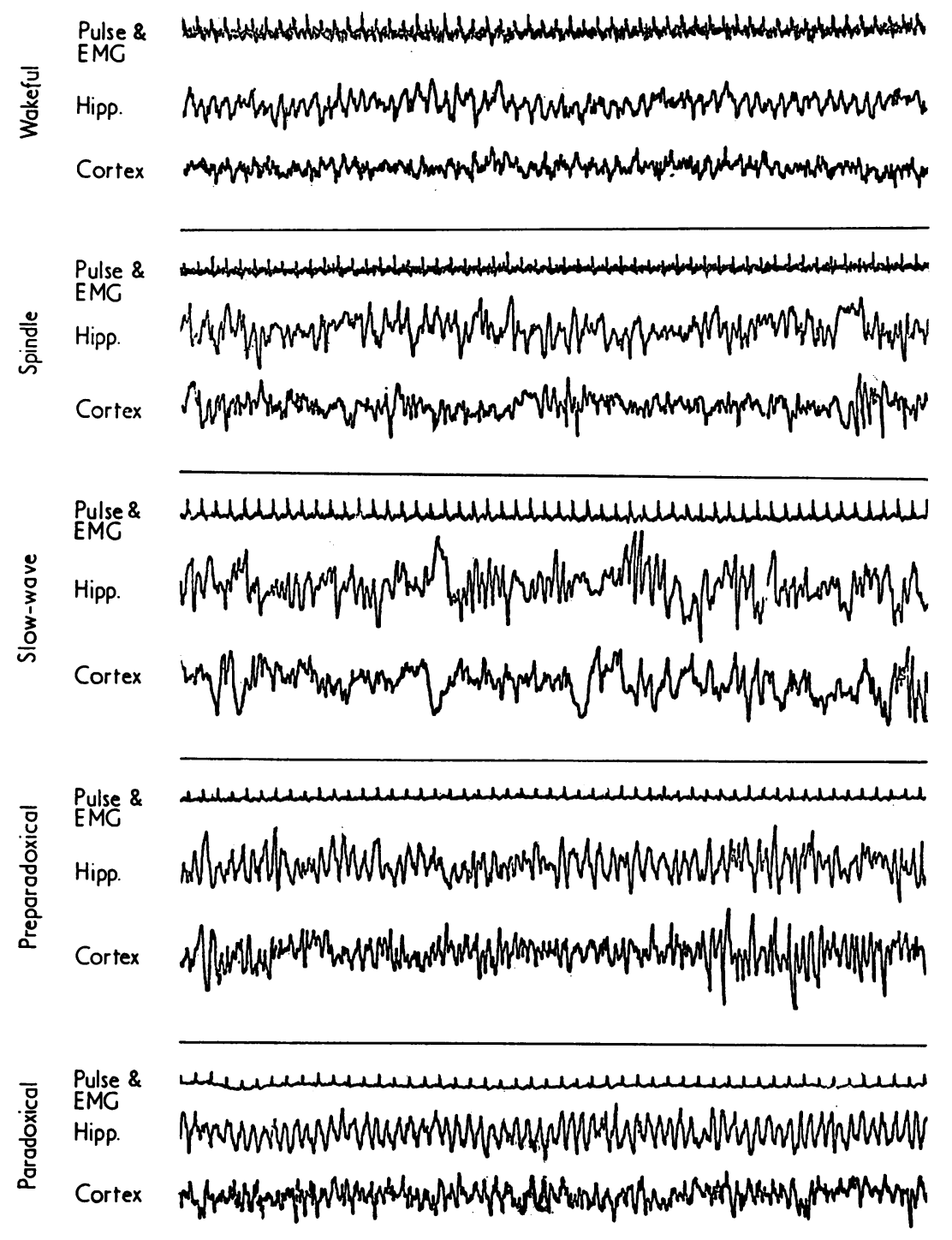

Fig. 2 Pulse, EMG and EEG from dorsal hippocampus and cortex in each phase of the sleep cycle.

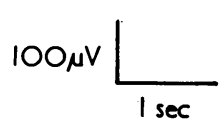

each phase in the control group showed very little change between the initial and the subsequent days. It was also found that the rat retained a certain sleep cycle under these conditions. The percentage of each phase was therefore compared for each individual with regard to the exposure day and the preceding day.

In the group exposed to $4000 \mathrm{ppm}$ toluene, all the sleep phases were drastically reduced and rarely appeared during the four hours' exposure or during the first two hours after exposure had ended. In the $2000 \mathrm{ppm}$ group, the wakeful phase significantly increased, while the spindle, slow-wave, preparadoxical and paradoxical phases all decreased significantly on the exposure day in comparison with those observed on the preceding day. 


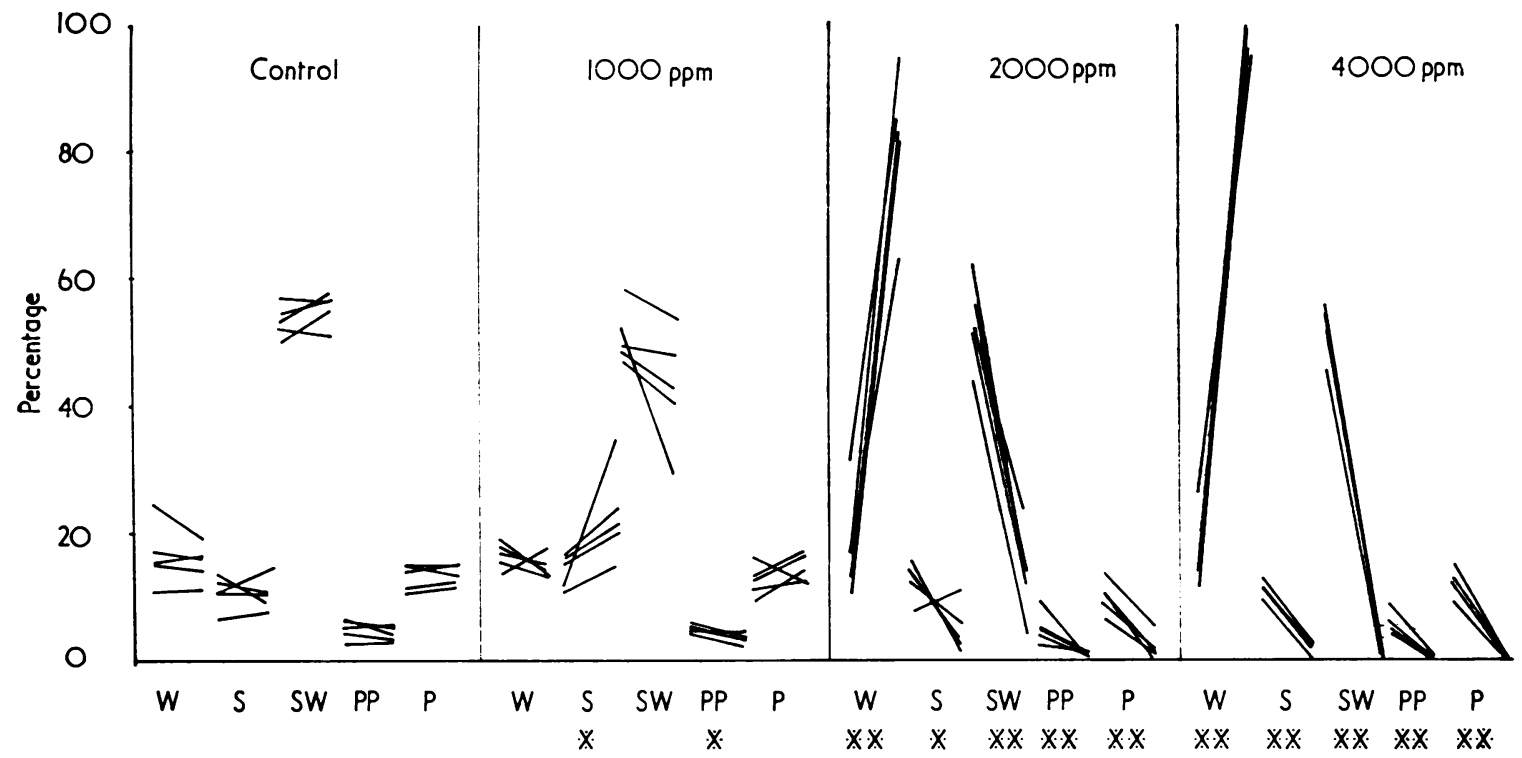

Fig. 3 Changes in the percentage of each phase of the sleep cycle during 4 hours' exposure and the first 2 hours after exposure to toluene. Significance level; ${ }^{* *} \mathrm{P}<0.01 * \mathrm{P}<0.05$. Lines show the transition from the preceding to the exposure day $(P-E)$. Sleep cycle phases: $W=$ wakeful; $S=$ spindle; $S W=$ slow-wave; $P P=$ preparadoxical; $\boldsymbol{P}=$ paradoxical.

In the group exposed to $1000 \mathrm{ppm}$, the preparadoxical phase significantly decreased and the spindle phase significantly increased on the exposure day in comparison with the preceding day. The paradoxical phase tended to increase during all six hours, and this increase differed significantly during the first two hours after the end of exposure from that noted on the preceding day.

Cortical and hippocampal EEGs were analysed at 10-second intervals by an EEG frequency analyser. The results were recorded continuously; eight samples were measured every 30 minutes. The $\mathbf{4 0 0 0}$ ppm and $2000 \mathrm{ppm}$ groups were measured in their wakeful phases and the $1000 \mathrm{ppm}$ and control groups in their slow-wave phases. The mean values of the eight samples were compared intraindividually. The changes in values are shown in Figs. 4-7.

In the $4000 \mathrm{ppm}$ toluene exposure group, the $\delta_{1}$ component diminished, while the $\beta_{1}$ and $\beta_{2}$ cortical components increased significantly in comparison with the control; the hippocampal $\theta, \beta_{1}$, and $\beta_{2}$ components significantly increased in comparison with the control (Fig. 4). In the $2000 \mathrm{ppm}$ group, the $\delta$ and $\alpha$ components of the EEG were reduced and the cortical $\beta_{2}$ component increased significantly in comparison with the control; the hippocampal $\delta_{1}$ component decreased and the $\theta$ component increased significantly in comparison with the control (Fig. 5). In the $1000 \mathrm{ppm}$ group, the cortical $\delta_{1}, \theta$ and $\alpha$ components were significantly reduced but the $\beta_{1}$ and $\beta_{2}$ components showed no significant change in comparison with the control; the hippocampal $\delta_{1}, \theta$, $\beta_{1}$ and $\beta_{2}$ EEG components decreased significantly but the $\alpha$ component showed no significant change in comparison with the control (Fig. 6). In the control group, the values of each component fluctuated slightly (Fig. 7).

The frequency of rhythmic hippocampal $\theta$ waves significantly decreased in the $4000 \mathrm{ppm}$ group but it did not change in the $2000 \mathrm{ppm}$ or $1000 \mathrm{ppm}$ groups (Fig. 8).

The total number of rearing reactions (standing on hind legs) was observed and taken as an index of the excitability level of the rat during the experiments (Irimiš et al., 1970). The results are shown in Fig. 9. In the $\mathbf{4 0 0 0} \mathrm{ppm}$ group the total number of the actions increased during the first hour of exposure, but after that it decreased rapidly as the rats became unable to stand or walk, and finally were unable even to crawl. However, the number of these actions increased again during the first hour after exposure, and significantly increased during the second hour after exposure in comparison with those recorded on the preceding day. In the $2000 \mathrm{ppm}$ group, the number of rearing reactions significantly increased from the second hour of exposure to the first hour after exposure in comparison with the preceding day. In the $1000 \mathrm{ppm}$ group, the total number 

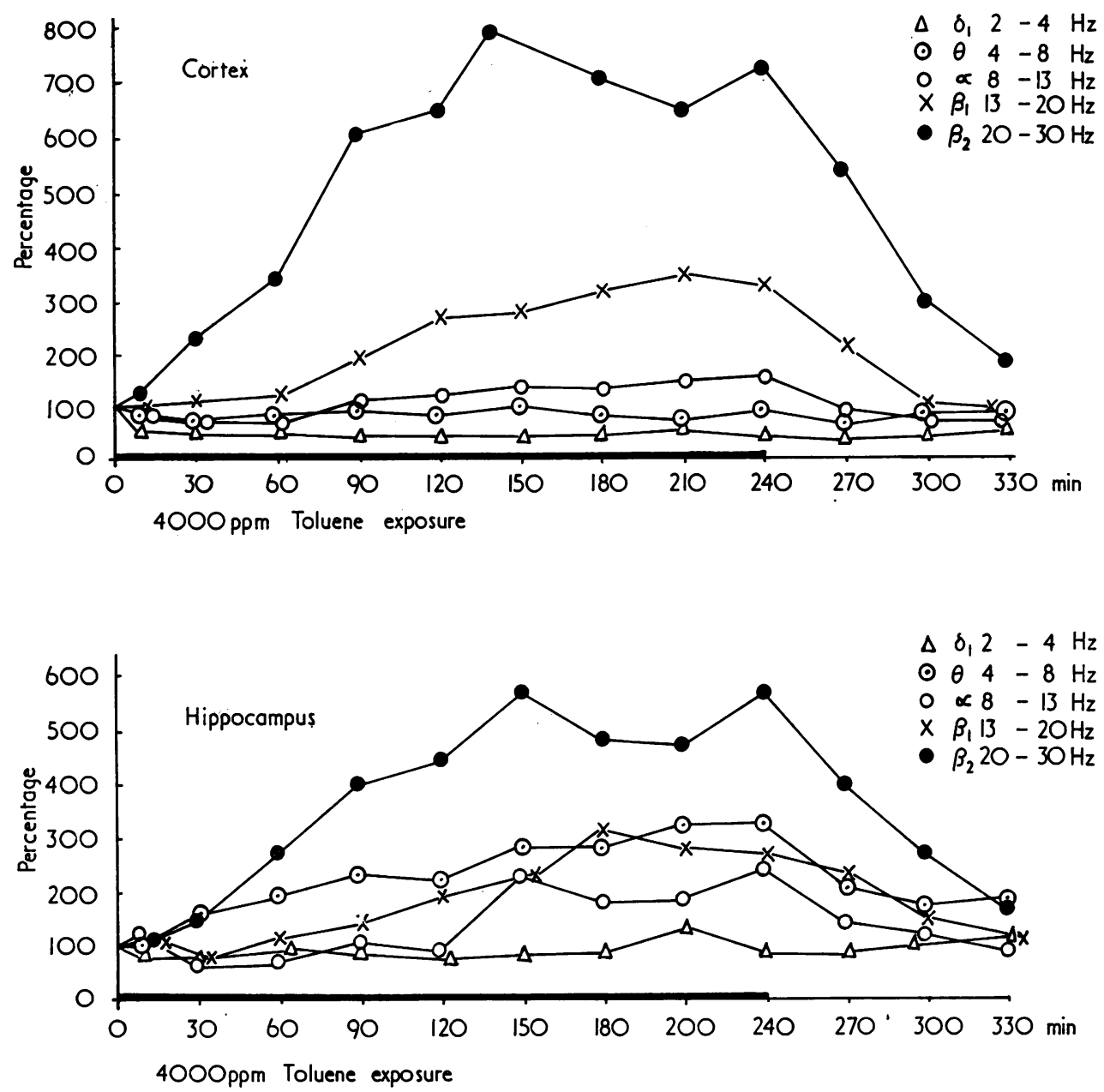

Fig. 4 Changes in each EEG component in rats exposed to 4000 ppm toluene for 4 hours (in the wakeful phase).

of rearing reactions slightly increased during the first hour of exposure but the increase was not statistically significant in comparison with the preceding day. In the control group there were very few rearing reactions, with no significant difference in this respect between the exposure day and the preceding day.

The pulse rate was measured at 10 -minute intervals. The pulse rate significantly increased in all rats in the $4000 \mathrm{ppm}$ and $2000 \mathrm{ppm}$ groups in comparison with the preceding day. In the $1000 \mathrm{ppm}$ group, it significantly increased in comparison with the preceding day in four out of five rats during exposure to toluene, and the increase was particularly marked during the latter half of the exposure. In the control group, the pulse showed hardly any change from day to day.
Myoclonic seizures were often observed in all rats during exposure to $4000 \mathrm{ppm}$ toluene. In the 2000 ppm group, myoclonic seizures were sometimes observed but not often. No myoclonic seizures were observed in rats exposed to $1000 \mathrm{ppm}$ toluene.

The rats in the $4000 \mathrm{ppm}$ group were unable to walk or crawl during the latter half of the exposure time. The rats in the $2000 \mathrm{ppm}$ group moved around at first, but became unsteady on their legs towards the end of the exposure time; some rats in the 1000 ppm group also were found to be slightly unsteady on their legs during the latter half of the exposure time. The behaviour of the control group showed very little change between the initial and subsequent days.

The results of the experiments are summarised in Fig. 10. 

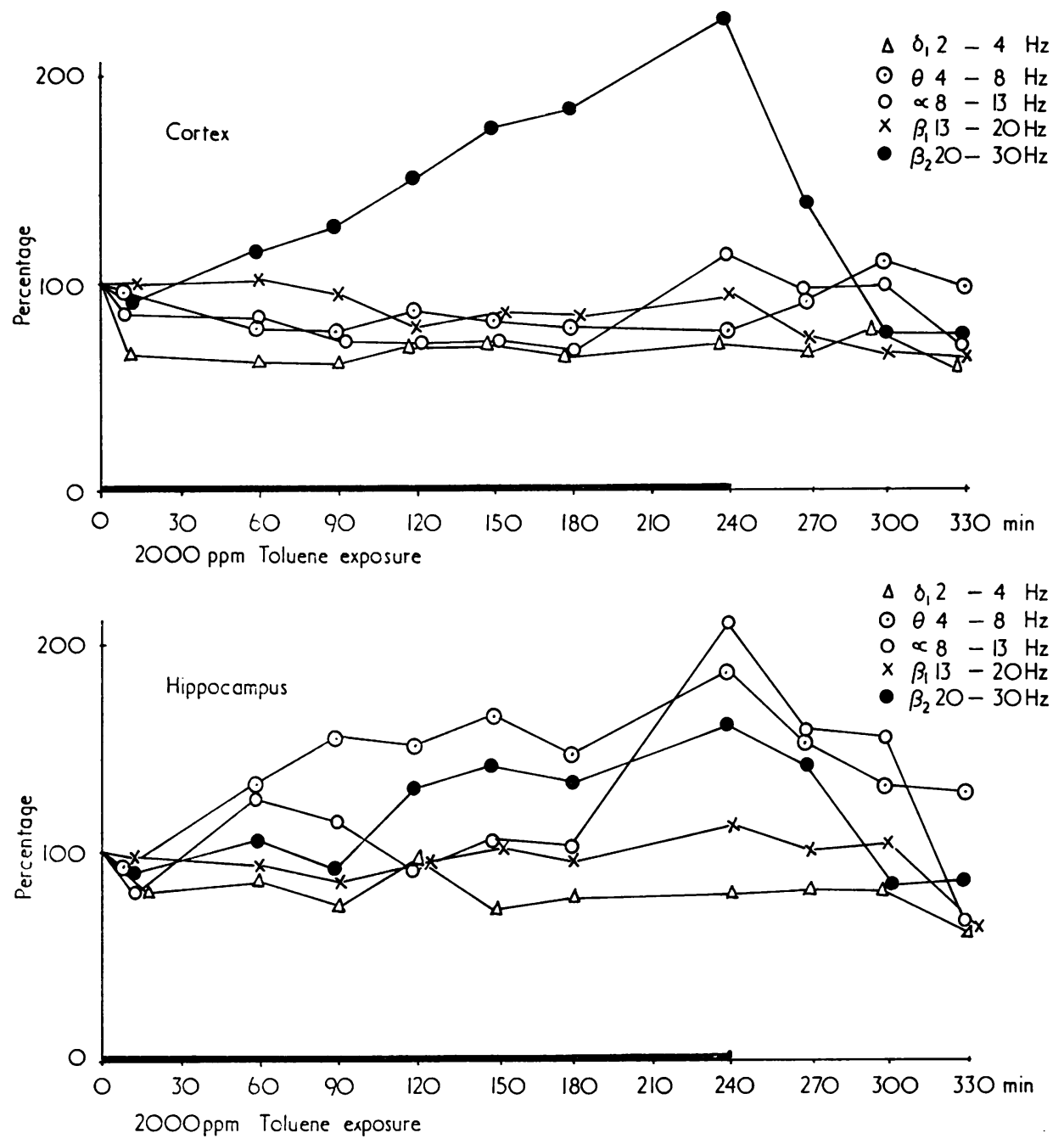

Fig. 5 Changes in each EEG component in rats exposed to 2000 ppm toluene for 4 hours (in the wakeful phase).

\section{Discussion}

Only two phases of sleep, that is, slow-wave sleep and paradoxical sleep, tend to be recognised (Jouvet and Jouvet, 1963; Jouvet, 1967). However, TimoIaria et al. (1970) described more phases, following a long series of studies of EEG, cervical EMG and eye movements of rats; these phases were named spindle, spindle and slow-wave, slow-wave, preparadoxical and paradoxical phases.

In the present experiments, the sleep cycle was divided into five phases, that is, wakeful, spindle, slow-wave, preparadoxical and paradoxical, on the basis of observations of cortical and hippocampal EEG, cervical EMG, and behaviour in rats, as it was considered not only to be difficult to classify the sleep state of rats into only two phases, but also to be important to observe the traditional stages of the cycle. The results suggest that the classification is useful for assessment of the effects of toluene on the central nervous system.

Regarding the changes in the sleep cycle brought about by toluene exposure, Fordor et al. (1973) recorded the EEG of rats at an extremely slow speed of $3 \mathrm{~cm} / \mathrm{min}$, which allowed them to give an exact differentiation by amplitude of three states of con- 

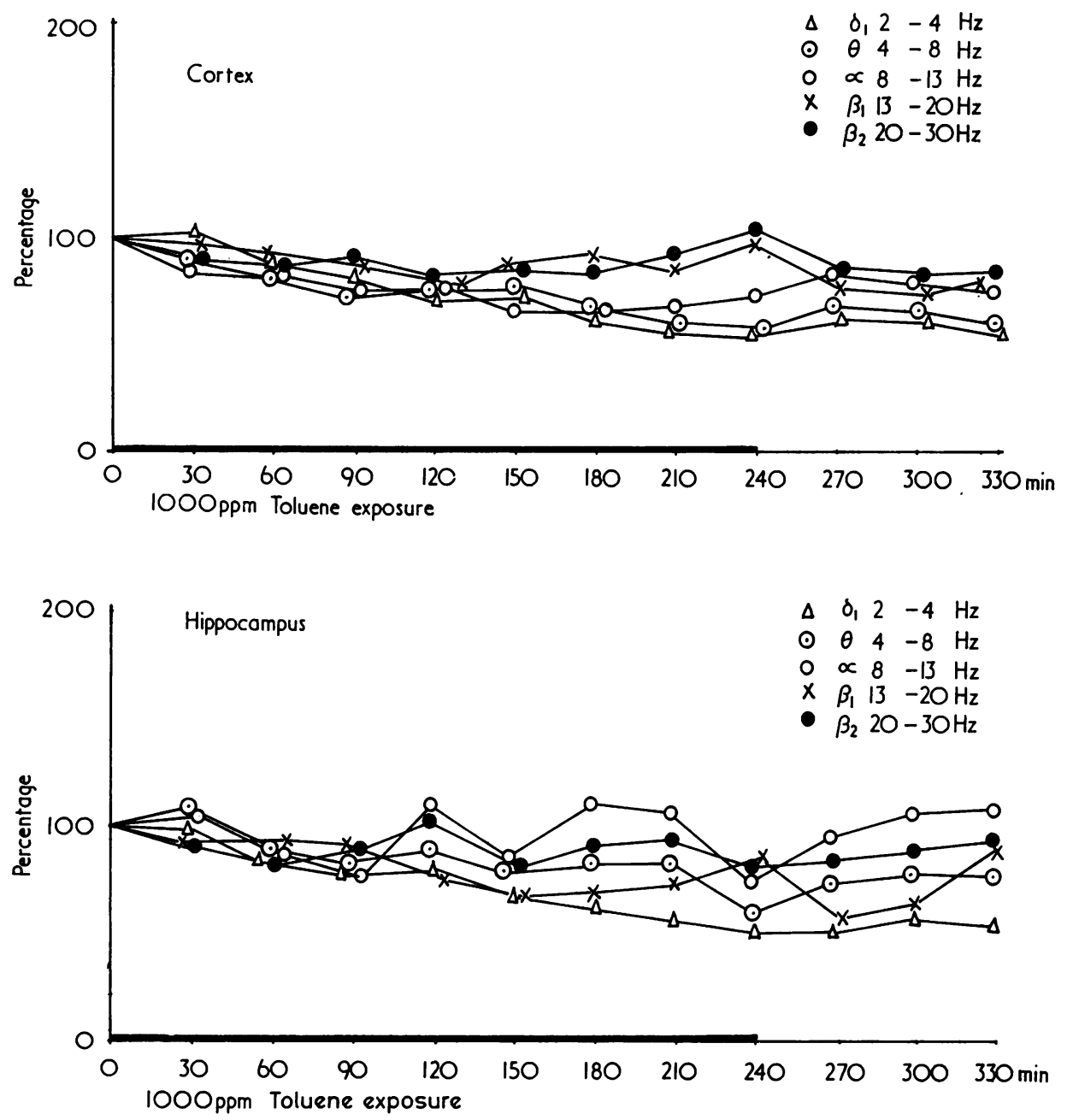

Fig. 6 Changes in each EEG component in rats exposed to 1000 ppm toluene for 4 hours (in the slow-wave phase).

sciousness, that is, NREM, REM and awake. These authors concluded that the first 24-hour values of a particular animal change only slightly during subsequent days of fresh air exposure. Analysis of variance during eight hours of the main sleeping time (from 800 am to $400 \mathrm{pm}$ ) demonstrated that the intraindividual fluctuations were small enough to be used for neurotoxicological assessment. These authors compared the effects of toluene (1000 ppm), dichloromethane (3000 ppm) and carbon monoxide (250 ppm), and reported that the REM showed an increase during eight hours' exposure to toluene, whereas the REM decreased with dichloromethane and carbon monoxide exposure.

In the present experiments, the percentage of each phase during the six hours of main sleeping time (from 1100 am to $500 \mathrm{pm}$ ) showed only a slight change during the same period on the following day when the animals were exposed to fresh air. An increase in the paradoxical phase was observed on exposure to $1000 \mathrm{ppm}$ toluene, the results being similar to those of Fordor et al. (1973), whereas all the sleeping phases showed a decrease on exposure to $2000 \mathrm{ppm}$ and $4000 \mathrm{ppm}$ toluene vapour. The results suggest that, while $1000 \mathrm{ppm}$ toluene may disturb the sleep and reduce a slow-wave phase, it tends to facilitate the paradoxical phase; 4000 $\mathrm{ppm}$ and $2000 \mathrm{ppm}$ toluene may disturb both types of sleep.

Jouvet (1969) postulates that the mammalian 

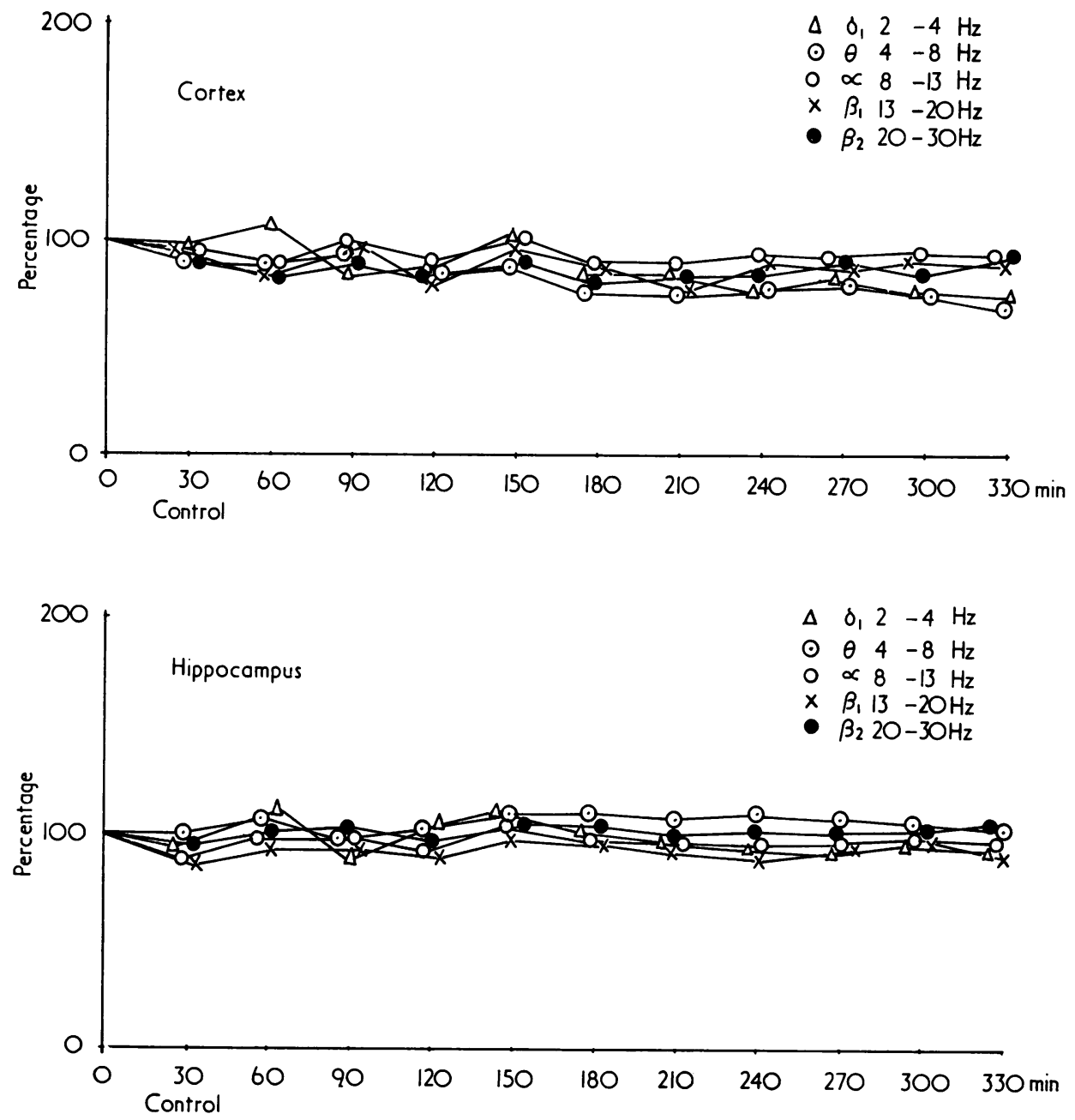

Fig. 7 Changes in each EEG component in the control rats (in the slow-wave phase).

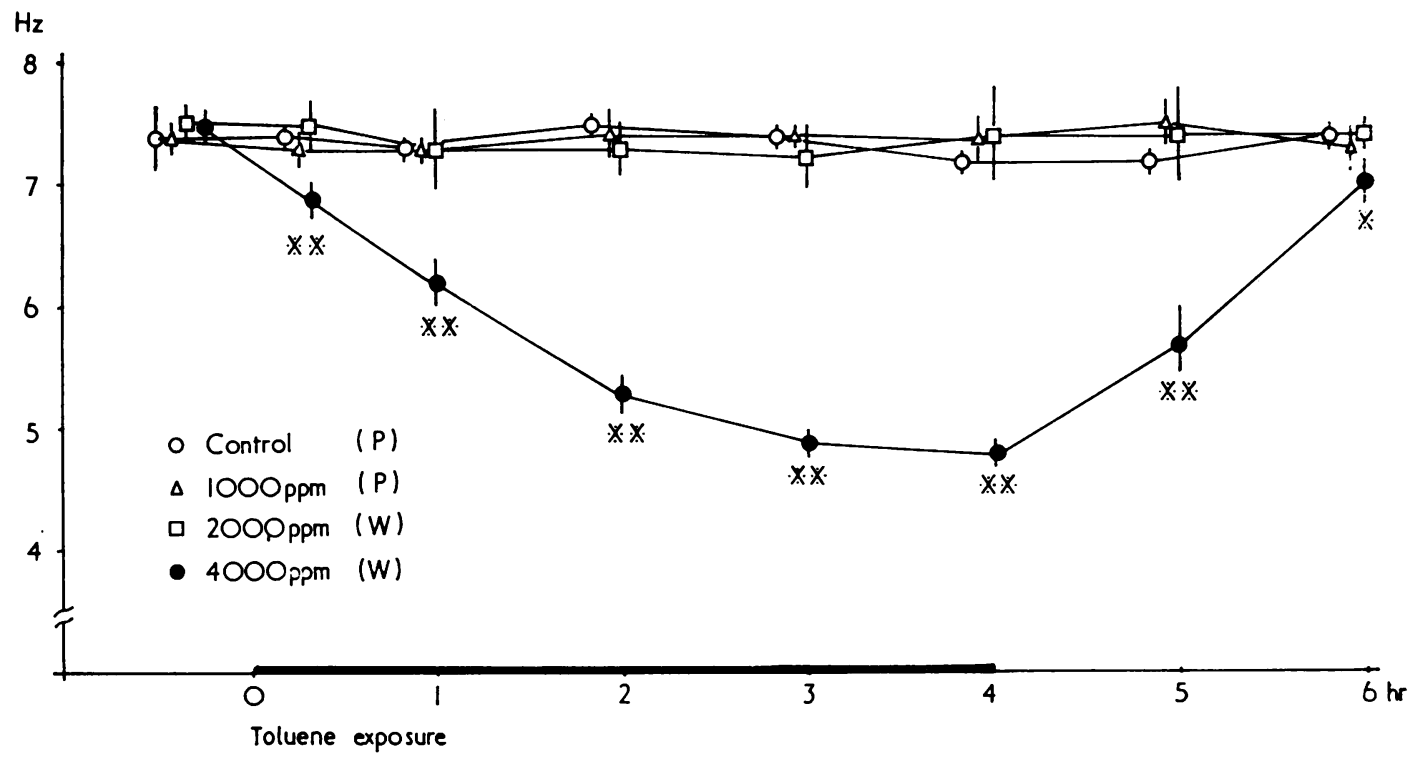

Fig. 8 Changes of frequency of the $\theta$ wave in the hippocampus of rats exposed to toluene (mean \pm S.E.). $P=$ paradoxical; $W=$ wakeful phase of sleep cycle. Significance level; ${ }^{* *} \mathrm{P}<0.01{ }^{*} \mathrm{P}<0.05$. 

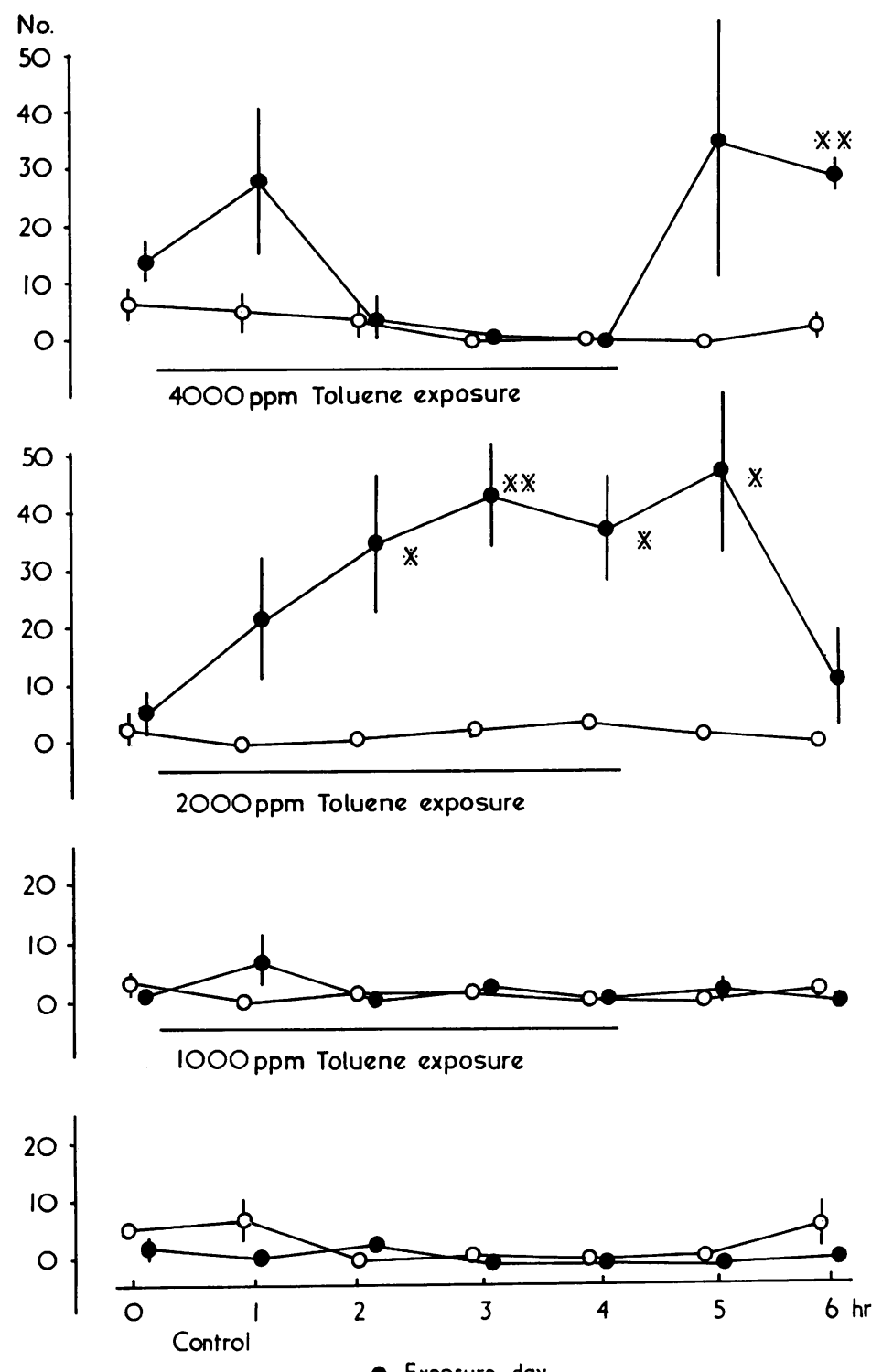

- Exposure day

- Precedina day

Fig. 9 Total number of rearing reactions (standing up on hind legs). Mean \pm S.E. Significance level; ${ }^{* *} \mathrm{P}<$ $0.01 * \mathrm{P}<0.05$.

brain undergoes cyclical biochemical changes, from the waking stage which depends upon the ascending reticular activating system, to slow-wave sleep which depends upon serotonin-containing neurones, and finally to paradoxical sleep which depends upon noradrenalin-containing neurones. Be that as it may, the analysis of changes caused by organic solvents in the sleep cycle may well be considered useful for clarification of the effects of solvents on the brain and the mechanism of sleep disturbance of those workers who are exposed to such solvents.

The changes in EEG components on toluene exposure were observed to be peculiarly characteristic for different concentrations. In the $4000 \mathrm{ppm}$ group, 


\begin{tabular}{|c|c|c|c|c|c|}
\hline & & $\underset{\mathrm{PPm}}{4000}$ & 2000 & 1000 & Control \\
\hline $\begin{array}{l}\text { Changes in } \\
\text { percentoge of } \\
\text { phases of } \\
\text { sleep cycle }\end{array}$ & \begin{tabular}{|c|} 
\\
$S$ \\
$S W$ \\
$P P$ \\
$P$ \\
\end{tabular} & & $\Omega$ & $\begin{array}{l}\text { ऽ } \\
\mathbb{Z}\end{array}$ & \\
\hline \multirow[b]{2}{*}{$\begin{array}{l}\text { Chonges in } \\
\text { components of } \\
\text { EEG }\end{array}$} & & $\mathrm{CH}$ & $\begin{array}{ll}\mathrm{C} & \mathrm{H} \\
\end{array}$ & $\mathrm{CH}$ & $\mathrm{CH}$ \\
\hline & \begin{tabular}{l|}
$\delta_{1}$ \\
$\theta$ \\
$\alpha$ \\
$\beta_{1}$ \\
$\beta_{2}$ \\
\end{tabular} & $\begin{array}{rr} & \\
& 1 \\
0 & 0 \\
1 & 1 \\
1 & 0 \\
\end{array}$ & $\begin{array}{|ll|}1 & 1 \\
& 1 \\
8 & \\
7\end{array}$ & $\begin{array}{ll}1 & 1 \\
2 & 2 \\
1 & \\
2 & \\
1 & \end{array}$ & \\
\hline \multicolumn{2}{|c|}{$\begin{array}{l}\text { Changes in frequency } \\
\text { of } \theta \text { wove in hippocampus }\end{array}$} & & & & \\
\hline \multicolumn{2}{|c|}{$\begin{array}{l}\text { Chonges in the total. } \\
\text { number of rearing reactions }\end{array}$} & $\Uparrow$ & & & \\
\hline \multicolumn{2}{|c|}{ Changes in pulse rote } & $\boldsymbol{T}$ & $\boldsymbol{t}$ & ७ & \\
\hline Sign & Ince le & & $P<0.01$ & & \\
\hline
\end{tabular}

Fig. 10 Summarised experimental results. $C=$ cortex; $H=$ hippocampus. Sleep cycle phases: $W=$ wakeful; $S=$ spindle; $S W=$ slow-wave; $P P=$ preparadoxical; $\boldsymbol{P}=$ paradoxical.

fast components increased markedly in the cortex, and so did the hippocampal $\theta$ and fast components. In the $2000 \mathrm{ppm}$ group, both the cortical fast components and the hippocampal $\theta$ components increased considerably, but in the $1000 \mathrm{ppm}$ group, almost all the cortical and hippocampal components decreased.

Regarding changes in $\theta$ components, Miyasaka et al. (1971) reported that glue-sniffers showed an irregular fast and low voltage at the early stage of sniffing, and sporadic $\theta$ waves or a burst of $\theta$ waves at the late stage of sniffing of solvent used as thinner (the chief component being toluene); a few patients showed continuously rhythmical $\theta$ waves of 6-7 $\mathrm{Hz}$ and gross rapid eye movements, with concurrent dreams and hallucinations. Ishiguro et al. (1974) observed that, even in deep anaesthesia, rhythmical hippocampal $\theta$ waves persisted continuously in most cats which had been treated with a thinner (predominantly toluene) and ketamine hydrochloride, while the waves flattened in cats treated with ether. Some authors also suggest that the persistence of the rhythmical hippocampal $\theta$ waves may have some connection with the psychomimetic effect of toluene.

In the present experiments, rhythmical hippocampal $\theta$ waves continued to occur during exposure to $4000 \mathrm{ppm}$ and $2000 \mathrm{ppm}$ toluene, and the frequency of these waves gradually decreased from $7 \cdot 1$ to $4.8 \mathrm{~Hz}$ in the $4000 \mathrm{ppm}$ group, but did not change in the $2000 \mathrm{ppm}, 1000 \mathrm{ppm}$ or control groups.

In the case of changes in fast waves, Hirano (1972c) reported that abnormal fast waves (about $20 \mathrm{~Hz}$ ) were observed in EEGs of patients with acute poisoning from a solvent thinner, the main ingredient of which was toluene. Mabuchi et al. (1974) reported that EEGs of 42 patients chronically poisoned with organic solvents showed abnormalities of basic rhythms in 30 patients and abnormal waves in 20. The abnormalities of basic rhythms were an irregular $\alpha$ wave mixed with fast waves in 10 patients, a diffuse $\alpha$ wave in 11, a low voltage fast wave pattern in six, a low voltage diffuse slow wave in one, and a high voltage $\alpha$ wave in two patients. Details of abnormal waves were also given: a sporadic slow wave in six, a high voltage slow wave burst in nine, a spike or spike and wave complex in five, and a $6 \mathrm{~Hz}$ positive spike in six patients.

In the present experiments, fast waves increased dramatically in rats during exposure to $2000 \mathrm{ppm}$ and $4000 \mathrm{ppm}$ toluene.

Direct comparisons between findings in humans and those in animals must always be made with caution, but the results of the present experiments suggest that the changes in basic EEG rhythms are significant findings which are detectable in both humans and animals that are exposed to high concentrations of toluene vapour. Further studies with chronically poisoned animals are desirable.

\section{References}

Andersen, P., and Kaada, B. R. (1953). The electroencephalogram in poisoning by lacquer thinner (butyl acetate and toluene). Acta Pharmacologica et Toxicologica, 9, 125-130.

Fordor, G. C., Schliplsörter, H. W., and Zimmerman, M. (1973). The objective study of sleeping behaviour in animals as a test of behavioural toxicology. In Adverse Effects of Environmental Chemicals and Psychotropic Drugs, vol. 1, pp. 115-123. Edited by M. Horváth. Elsevier: Amsterdam.

Hirano, H. (1972a). Electroencephalographic studies on a worker chronically exposed to thinner. Rinsho Noha (Clinical Electroencephalography), 14, 552-555 (in Japanese).

Hirano, H. (1972b). Electroencephalographic studies on workers exposed to organic solvents. Nihon Iji Shimpo (Japan Medical Journal), 2499, 48-50 (in Japanese).

Hirano, H. (1972c). Electroencephalograms in acute poisoning by organic solvents, Rinsho Noha (Clinical Electroencephalography), 14, 725-728 (in Japanese). 
Giuliano, G., Iannaccone, A., and Zoppoli, R. (1974). Electroencephalographic investigation of shoe industry workers exposed to the risk of poisoning from adhesives solvents. Lavoro Umano, 26, 33-42.

Irimiš, F., Radil-Weiss, T., Lát, J., and Krekule, I. (1970). Inter-individual differences in hippocampal theta activity during habituation. Electroencephalography and Clinical Neurophysiology, 28, 24-31.

Ishiguro, T., Katsuyuki, S., and Shimazono, Y. (1974). Study of the changes in behaviour and polygraphic analysis of cats induced by chronic exposure to organic solvents, thinner; comparison with the phenomena caused by ether and ketamine hydrochloride. Shinkei Kenkyu no Shimpo (Advances in Neurological Sciences), 18, 122-136 (in Japanese with English Abstract).

Jouvet, M., and Jouvet, D. (1963). A study of the neurophysiological mechanisms of dreaming. Electroencephalography and Clinical Neurophysiology. Suppl., 24, 133-157.

Jouvet, M. (1967). Neurophysiology of the states of sleep. Physiological Reviews, 47, 117-177.

Jouvet, M. (1969). Biogenic amines and the states of sleep. Science, 163, 32-41.

König, J. F. R., and Klippel, R. A. (1963). The Rat Brain; a Stereotaxic Atlas of the Forebrain and Lower Parts of the Brain Stem, pp. 1-162. Williams and Wilkins: Baltimore.

Mabuchi, C., Takagi, S., and Usui, T. (1972). Electroencephalograms in chronic poisoning by organic solvents. Rinsho Noha (Clinical Electroencephalography), 14, 343-350 (in Japanese).

Mabuchi, C., Takagi, S., Takeuchi, Y., Koike, Y., Yamauchi, K., and Shibata, T. (1974). Neurological symptoms in chronic intoxication by organic solvents. Igaku no Ayumi
88, 97-106 (in Japanese).

Maeda, K. (1968). Gas chambers for the exposure of animals to organic solvents. Japanese Journal of Industrial Health, 10, 427-432 (in Japanese with English abstract).

Miyasaka, M., Kojima, T., Shimazono, Y., Kido, M., Sugano, Y., and Hayashi, M. (1971). Electroencephalographic and polygraphic studies on sniffers of thinner-bond. Rinsho Noha (Clinical Electroencephalography), 13, 371-372 (in Japanese).

Roldán, E., Weiss, T., and Fifková, E. (1963). Excitability changes during the sleep cycle of the rat. Electroencephalography and Clinical Neurophysiology, 15, 775-785.

Suzuki, H. (1973). Autonomic nervous responses to experimental toluene exposure in humans. Japanese Journal of Industrial Health, 15, 379-384 (in Japanese with English abstract).

Takeuchi, Y., Nishizaki, S., Takagi, S., and Mabuchi, C. (1972a). Diencephalic syndrome in two workers exposed mainly to toluene vapour. Japanese Journal of Industrial Health, 14, 563-571 (in Japanese with English abstract).

Takeuchi, Y., Tanaka, T., Matsumoto, T., and Matsushita, T. (1972b). Experimental studies on the response of the diencephalon-hypophysis-adrenal cortex system in exposure to toluene vapour. Japanese Journal of Industrial Health, 14, 543-553 (in Japanese with English abstract).

Takeuchi, Y., and Suzuki, H. (1975). Changes of convulsion threshold in the rat exposed to toluene. Industrial Health, 13, 109-114.

Timo-Iaria, C., Negrão, N., Schmidek, W. R., Hoshino, K., Lobato de Menezes, C. E., and Leme da Rocha, T. (1970). Phases and states of sleep in the rat. Physiology and Behaviour, 5, 1057-1062. 